\title{
CORRECTION
}

\section{Correction to: ACMG SF v3.0 list for reporting of secondary findings in clinical exome and genome sequencing: a policy statement of the American College of Medical Genetics and Genomics (ACMG)}

David T. Miller, Kristy Lee, Wendy K. Chung, Adam S. Gordon, Gail E. Herman, Teri E. Klein, Douglas R. Stewart, Laura M. Amendola, Kathy Adelman, Sherri J. Bale, Michael H. Gollob, Steven M. Harrison, Ray E. Hershberger, Kent McKelvey, C. Sue Richards, Christopher N. Vlangos, Michael S. Watson, Christa Lese Martin and ACMG Secondary Findings Working Group*

Genetics in Medicine (2021) 23:1582-1584; https://doi.org/10.1038/s41436-021-01278-8

Correction to: Genetics in Medicine 2021; https://doi.org/10.1038/ s41436-021-01172-3; published online 20 May 2021

Unfortunately an error occurred in Table 2 and 3 . The correct Table 2 and 3 are given below.

In addition, on page 2 of the article (right column, fifth paragraph, third sentence), the phrase "deletions of" has been added. The correct sentence is given below. Other technical difficulties were noted for genes such as EPCAM associated with Lynch syndrome and GREM1-associated polyposis, where routine detection of common deletions or duplications could be difficult at this time by ES/GS in many laboratories. On page 7 of the article (right column, third paragraph, fifth sentence), the word "high" should be replaced by "low". The correct sentence is given below. MODY3 does not require insulin treatment and responds well to low dose oral sulfonylureas, typically lower doses than are customary for most type 2 diabetics. On page 8 of the article (left column, third paragraph, second sentence), the word "SERPINC1" should be replaced by "SERPINA1". The correct sentence is given below. The SFWG decided that including gene phenotypes such as $H M B S$-associated acute intermittent porphyria and SERPINA1/alpha-1-antitrypsin deficiency with interventions involving environmental exposures or behavior modification was beyond the scope of this list.

The original article has been corrected.

\section{ADDITIONAL INFORMATION}

Supplementary information The online version contains supplementary material available at https://doi.org/10.1038/s41436-021-01278-8.

Correspondence and requests for materials should be addressed to ACMG

Reprints and permission information is available at http://www.nature.com/ reprints 
Table 2. New gene-phenotype pairs for secondary findings (SF) list.

Gene-phenotype

\section{Genes related to cancer phenotypes}

$M A X /$ hereditary paraganglioma/pheochromocytoma

PALB2/hereditary breast cancer

TMEM127/hereditary paraganglioma/pheochromocytoma

\section{Genes related to cardiovascular phenotypes}

CASQ2/catecholaminergic polymorphic ventricular tachycardia (CPVT)

\section{FLNC/cardiomyopathy}

$T R D N /$ catecholaminergic polymorphic ventricular tachycardia (CPVT) \& long QT syndrome

$\pi T /$ cardiomyopathy

\section{Genes related to inborn errors of metabolism phenotypes}

$B T D /$ biotinidase deficiency

GAA/Pompe disease

\section{Genes related to miscellaneous phenotypes}

ACVRL 1/hereditary hemorrhagic telangiectasia

ENG/hereditary hemorrhagic telangiectasia

HFE/hereditary hemochromatosis (HFE p.C282Y

homozygotes only)

HNF1A/maturity-onset diabetes of the young (MODY3)

RPE65/RPE65-related retinopathy
Key considerations

Penetrance met threshold to include with other PGL/PCC genes

Risk of breast cancer risk meets penetrance threshold

Penetrance met threshold to include with other PGL/PCC genes

Risk of sudden death with preventive interventions available

Risk of sudden death with preventive interventions available

Risk of sudden death with preventive interventions available

Risk of sudden death with preventive interventions available

Features can be nonspecific; highly effective treatment in children and adults Availability of effective enzyme replacement therapy in infantile and lateronset cases

Potential morbidity meets penetrance threshold and has efficacious intervention

Potential morbidity meets penetrance threshold and has efficacious intervention

Potential morbidity meets penetrance threshold and has efficacious intervention

Accounts for $30-50 \%$ of known MODY cases likely to respond to low dose sulfonylureas; early treatment may prevent complications

Availability of gene therapy treatment that may be more efficacious earlier in disease progression

PGL/PCC paraganglioma/pheochromocytoma. 
Table 3. Genes not selected for secondary findings (SF) list v3.0 and reasoning.

\begin{tabular}{|c|c|c|}
\hline Gene-phenotype & Category & Additional comments \\
\hline \multicolumn{3}{|l|}{ Technical concerns } \\
\hline EPCAM-associated Lynch syndrome & Cancer & Concern that deletions or duplications would be difficult to detect by NGS \\
\hline GREM1-related polyposis & Cancer & $\begin{array}{l}\text { Concern that duplication would be difficult to detect with NGS and overall } \\
\text { limited information about this gene }\end{array}$ \\
\hline $\begin{array}{l}\text { HNF1B-related maturity-onset diabetes of the } \\
\text { young (MODY5) }\end{array}$ & Miscellaneous & $\begin{array}{l}\text { Accounts for } \sim 5 \% \text { of known MODY with } \sim 50 \% \text { of cases associated with } \\
\text { deletions difficult to detect on exome sequencing }\end{array}$ \\
\hline $\begin{array}{l}\text { SDHA/hereditary paraganglioma/ } \\
\text { pheochromocytoma }\end{array}$ & Cancer & $\begin{array}{l}\text { Concerns about presence of many pseudogenes that could lead to false } \\
\text { positive results that would require labs to perform extensive validation work }\end{array}$ \\
\hline \multicolumn{3}{|l|}{ Penetrance concerns } \\
\hline BRIP1/RAD51C/RAD51D-related ovarian cancer & Cancer & $\begin{array}{l}\text { Lack of effective surveillance modalities for ovarian cancer also a } \\
\text { consideration }\end{array}$ \\
\hline DICER1-associated tumors & Cancer & Challenges in DICER1 missense variant interpretation \\
\hline $\begin{array}{l}\text { HFE-related hemochromatosis (except for HFE p. } \\
\text { C282Y homozygotes) }\end{array}$ & Miscellaneous & Penetrance is driven by the p.Cys282Tyr variant, and not other variants in HFE \\
\hline TTR-amyloidosis & Miscellaneous & $\begin{array}{l}\text { Also considered that sudden death was rare, thus allowing time for clinical } \\
\text { diagnosis }\end{array}$ \\
\hline \multicolumn{3}{|l|}{ Clinical management concerns } \\
\hline$A B C D 1 \mathrm{X}$-linked adrenoleukodystrophy & IEM & $\begin{array}{l}\text { Severe cases have early onset and would be diagnosed by newborn } \\
\text { screening; no specific treatment in adulthood }\end{array}$ \\
\hline$B A P 1$-related tumors & Cancer & $\begin{array}{l}\text { Small number of families reported to date and no established consensus } \\
\text { management recommendations as of time reviewed }\end{array}$ \\
\hline COL5A1-associated Ehlers-Danlos syndrome & Miscellaneous & Not considered highly actionable \\
\hline GCH1-related dopa-responsive dystonia & Miscellaneous & $\begin{array}{l}\text { Concern that diagnosis of the classic phenotype is relatively straightforward } \\
\text { and that the treatment efficacy was not dependent on the timing of initiation }\end{array}$ \\
\hline HMBS-associated acute intermittent porphyria & Miscellaneous & $\begin{array}{l}\text { Concern that avoidance of exposures and delays in diagnosis could be out of } \\
\text { scope for the ACMG SF list }\end{array}$ \\
\hline MEFV-associated familial Mediterranean fever & Miscellaneous & $\begin{array}{l}\text { Concern about clinical management of acute episodes being primarily } \\
\text { supportive, and diagnosis could then be made through diagnostic testing }\end{array}$ \\
\hline NOTCH3/CADASIL & Miscellaneous & Not considered highly actionable \\
\hline POLD1/POLE-related polyposis & Cancer & $\begin{array}{l}\text { Rarity of known pathogenic variants that could be reported and uncertain } \\
\text { risks of extracolonic cancers }\end{array}$ \\
\hline PRKAR1A/Carney complex & Miscellaneous & Concerns about penetrance and questions about actionability \\
\hline SERPINA1-related alpha-1-antitrypsin deficiency & Miscellaneous & $\begin{array}{l}\text { Concern that avoidance of exposures could be out of scope for the ACMG } \\
\text { SF list }\end{array}$ \\
\hline
\end{tabular}

ACMG American College of Medical Genetics and Genomics, IEM inborn errors of metabolism, NGS next-generation sequencing. 